\title{
INFECCIÓN CONGÉNITA POR CITOMEGALOVIRUS
}

Héctor Romero MD*, Girlesa Ruiz MD**, Maria Emilia Contreras MD**

\section{Resumen}

Este artículo presenta el estado del arte de la infección congénita por citomegalovirus en recién nacidos, considerada de importante prevalencia en la población. Se documentan las características más relevantes y algunos aspectos relacionados con la inmunidad y la epigenética del virus para facilitar el entendimiento de la patogenia, el tratamiento y las secuelas. Con ello se proporcionan herramientas para la identificación de los factores de riesgo y de las principales manifestaciones clínicas tanto en la infección sintomática como en la asintomática, para que el clínico mejore el diagnóstico e incida en el pronóstico del curso de la infección. Se hace referencia a los lineamientos y recomendaciones actualizadas para la prevención, tratamiento y seguimiento de los pacientes en riesgo y con infección instaurada.

Palabras clave: citomegalovirus, infección congénita, neonatos.

Abreviaturas: CMV, citomegalovirus; RN, recién nacido (s); CM VH, citomegalovirus humano.

\section{CONGENITAL CYTOMEGALOVIRUS INFECTION}

\section{Abstract}

This article presents the state-of-the-art on neonatal congenital cytomegalovirus infection which is considered of major prevalence in this age group. Most relevant features and some immunity and epigenetics aspects of the virus are described in order to increase understanding on pathogenesis, treatment and sequelae. Thus it provides tools to identify risk factors and major clinical manifestations of both symptomatic and aymptomatic infection for the clinician to improve diagnosis and influence prognosis of the course of this infection. Updated guidelines and prevention, treatment and follow-up recommendations for high-risk patients and infected patients are discussed.

Key words: cytomegalovirus, congenital infection, neonates.

Fecha recibido: abril 13 de 2013 - Fecha aceptado: agosto 12 de 2013

* Pediatra Hospital de San José. Instructor Asociado, Fundación Universitaria de Ciencias de la Salud, Bogotá DC, Colombia.
** Residente III de Pediatría, Fundación Universitaria de Ciencias de la Salud, Bogotá DC, Colombia. 


\section{Introducción}

La infección por CMV en RN pese a tener referentes en la literatura científica en relación con el diagnóstico, tratamiento y pronóstico, carece de relevancia desde el punto de vista de políticas en salud pública con miras a incidir en el decrecimiento del riesgo, de las secuelas relacionadas con el desarrollo psicomotor e incluso de la misma mortalidad infantil, como si se evidencia en casos de toxoplasmosis y sífilis pertenecientes al grupo STORCH (sífilis, toxoplasma, rubeola, CMV y herpes).

En consecuencia, resulta pertinente presentar una revisión de la literatura sobre el tema con el fin de enriquecer el conocimiento de esta enfermedad congénita, tanto en el ámbito de los profesionales de la salud como en el de aquellos que tienen relación directa e indirecta con las referidas políticas de salud pública.

Para la consecución de este fin, realizamos una investigación sistemática y actualizada del estado del arte a partir de la generación de descriptores en ciencias de la salud que facilitaron el uso de terminología común en tres idiomas: español, inglés y portugués. Después se identificaron las bases de datos de Hinari con enlace Pubmed, Scopus y Scielo, las cuales permitieron abarcar el mayor número de artículos en los últimos cinco años. De la búsqueda realizada se consolidó una base de 57 artículos que fueron sistematizados para la construcción de la presente revisión.

\section{Generalidades}

El CMV es un subgénero del herpes, también conocido como el herpes 5 (HHV-5), que se encuentra encapsulado en una molécula bicatenaria $\beta$-ADN. ${ }^{1}$ Su genoma está dividido en una región única larga (UL) y otra única corta (US), indispensables para la síntesis de la proteína UL54 (DNA polimerasa). ${ }^{2}$

La envoltura exterior de este virus derivada de la membrana nuclear de la célula huésped, contiene glicoproteínas B (gB) y H (gH), consideradas como determinantes principales de la inmunidad humoral, por lo que los anticuerpos contra estas proteínas son capaces de neutralizar el virus, lo cual explica que se encuentren en estudio para el desarrollo de vacunas. ${ }^{2}$ El mecanismo de replicación es lento, se efectúa en cultivos celulares y acorde con las investigaciones se divide en tres etapas. La primera denominada inmediata precoz, se desarrolla en las primeras cuatro horas después de la infección, en la que se sintetizan las proteínas virales; en la segunda o fase precoz, se sintetizan las proteínas para la replicación de ADN y proteínas estructurales; y en la tardía, que ocurre alrededor de 24 horas después de la infección, se sintetizan las proteínas relacionadas con el ensamblaje de la envoltura viral. ${ }^{3}$

En este proceso de infección por CMV, al inicio el virus se adhiere a la superficie de la célula huésped por la interacción entre la membrana y una molécula celular que funciona como receptor. Luego atraviesa la membrana plasmática, lo que se conoce en su ciclo de vida como penetración, y por último el ADN viral entra al núcleo de manera que los genes MCMV se expresan en tres fases secuenciales; temprana inmediata, temprana y tardía.

Las vías de transmisión del CMV son a través de contacto cerrado entre individuos, en especial a través de contaminación a partir de orina, saliva, semen, secreciones cervicales, transfusión sanguínea, trasplante de órganos y lactancia materna ${ }^{4,5}$, aunque existen otras menos frecuentes como vía aérea a través de gotas. ${ }^{6}$

Durante la gestación, en la etapa temprana de la embriogénesis, se encuentran dos rutas principales de infección al embrión. La primera es directa in útero, esto es durante la fertilización y la implantación, toda vez que el semen eyaculado puede contener particulares virales que pueden infectar al embrión. La segunda es a través de la placenta. ${ }^{7}$ También juega un papel importante la velocidad de transmisión vertical. Esto parece aumentar con la edad gestacional: $36 \%$ en el primer trimestre, $44 \%$ en el segundo y $77,6 \%$ en el último trimestre. Sin embargo, las consecuencias de la infección por CMV son más graves cuando la infección materna ocurre antes de la semana veinte. ${ }^{8}$

Cuando se adquiere por transfusión de sangre infectada puede producir importantes complicaciones en pre- 
maturos. El riesgo de infección es más elevado cuanto mayor sea el número de unidades de sangre transfundidas y el de donantes. Los servicios neonatales y los bancos de sangre utilizan diferentes estrategias preventivas, como los filtros de leucocitos, los hemoderivados de donante CMV-negativo y las políticas de reducción del número de transfusiones y donantes. ${ }^{9}$

Alrededor del $1 \%$ de los RN y entre 5 y $10 \%$ de los lactantes eliminan CMV en orina, mientras que esto ocurre en más del 10\% de los RN prematuros hospitalizados durante más de un mes. La transmisión de paciente a paciente es posible a través de las manos del personal sanitario. No obstante, el CMV se elimina con jabón y soluciones alcohólicas, de modo que una correcta higiene de manos hace que la transmisión sea poco frecuente. De hecho, la infección posnatal en prematuros de madres seronegativas y sin riesgo de transmisión por productos sanguíneos es muy rara. ${ }^{9}$

La exposición repetida al virus a través de la saliva o superficies contaminadas con ella ocurre en centros de cuidado infantil. Los infectados después del nacimiento con CMV eliminan virus en orina en promedio a los 18 meses (rango 6-40 meses). ${ }^{10}$

Una vez que se da la infección primaria, hay periodos de latencia y reactivación, de manera que la transmisión al feto o al recién nacido puede ocasionarse como primoinfección o como recurrencia, aunque la primera es más frecuente por la transmisión intrauterina o la lactancia materna. ${ }^{11} \mathrm{El}$ mecanismo de excreción de CMV en la leche es desconocido y por lo regular se detecta solo en esta y no en orina ni en saliva; los estudios serológicos muestran anticuerpos IgG y ausencia de anticuerpos IgM. Así, la reactivación parece tener lugar en la propia glándula mamaria. ${ }^{9}$

\section{La infección congénita por CMV}

\section{Definición y Epidemiología}

Constituye una causa conocida de morbilidad y mortalidad perinatal. El CMV puede transmitirse al pasar por el canal del parto o a través de la leche materna, las transfusiones sanguíneas y otras fuentes. ${ }^{9}$ Es la infección congénita más frecuente en los países de- sarrollados, con una prevalencia que oscila entre 0,3 y $2,4 \%$ de los RN. Las tasas son más altas en Estados Unidos y menores en Europa, donde se sitúan entre 0,3 y $0,6 \%$. Debido a su alta prevalencia, el tipo congénito es una de las causas más frecuentes de retraso psicomotor y sordera neurosensorial de origen infeccioso. ${ }^{12}$ Aunque puede ocurrir como resultado de una infección materna primaria por CMV, reactivación o reinfección y transmisión madre-hijo, la forma primaria constituye el mayor riesgo, que varía entre 14,2 y $52,4 \%$. Cada año cerca de 1 a $7 \%$ de las embarazadas contraen una infección primaria por CMV. Alrededor de 10 a $15 \%$ de los RN infectados son sintomáticos y tienen una tasa de mortalidad de $10 \%$ De los bebés que sobreviven 70 a 80\%, desarrollan importantes secuelas neurológicas. Cerca de 85 a $90 \%$ son asintomáticos y de 8 a $15 \%$ sufrirán alteración en el desarrollo psicomotor y discapacidad neurosensorial. ${ }^{13}$

Cada año en EE.UU se estima que 30.000 niños nacen con infección congénita por CMV $(0,7 \%$ de todos los $\mathrm{RN}$ ), causando un estimado de 300 muertes y 6.000 discapacitados permanentes, como pérdida de audición, de visión o retraso mental. Afecta más población que otros trastornos de la infancia como el Down (4.000 por año), el síndrome de alcoholismo fetal (5.000 por año) o la espina bífida (3.500 por año). ${ }^{14}$

Se estima que alrededor de 40.000 niños nacen con CMV, resultando en cerca de 400 casos fatales por año. Solo 10 a $15 \%$ presentan al nacer signos clínicos, aunque incluso los que parecen asintomáticos están en riesgo de secuelas neurológicas. La mayoría (60 a $90 \%$ ) con infección sintomática y 10 a $15 \%$ asintomáticos que pueden desarrollar a largo plazo una o más secuelas neurológicas, como retraso mental o psicomotor y anormalidades oftalmológicas. Las estimaciones actuales indican que 8.000 niños se ven afectados cada año por alguna de estas relacionadas con infección por CMV en el útero. ${ }^{15}$

En Estados Unidos, la seroprevalencia general del CMV se estima en cerca de $50 \%$, dejando a muchas mujeres en edad reproductiva en riesgo de la infección primaria por CMV durante el embarazo. La seroprevalencia mundial en mujeres en edad fértil es de $45 \%$ 
en países desarrollados y $100 \%$ en aquellos en desarrollo. El estado socioeconómico alto se asocia con tasas más bajas. ${ }^{10}$

En Chile la prevalencia reportada para mujeres mayores de 20 años es $75 \%$ y una incidencia de infección congénita de $1,82 \%$ El riesgo de transmisión vertical es de $40 \%$ en la primoinfección y de 0,2 a $8 \%$ en la recurrencia. La transmisión varía según la edad gestacional, siendo más alta durante el tercer trimestre. En pacientes seropositivas el riesgo de reactivación se produce por compromiso de la inmunidad celular (linfocitos T), lo que se observa en inmunocomprometidas, tales como pacientes VIH positivas, oncológicas o en tratamiento con inmunosupresores. ${ }^{15,16}$

\section{Factores de riesgo}

En concordancia con la alta prevalencia que se reporta en la infección congénita por CMV se han identificado algunos factores asociados, que no son ni muy específicos ni tampoco predictivos; tal es el caso de la edad temprana o el estatus de soltera al momento de presentarse la primera gestación, a lo que se agrega el bajo nivel socioeconómico de la gestante. ${ }^{17}$ En la literatura científica se ha reportado que la seroprevalencia materna para CMV incrementa con la edad, hasta cifras cercanas a $80 \%$ a la edad de 60 años ${ }^{15}$, en lo cual inciden en el número de gestaciones, el desarrollo de determinadas actividades profesionales, como el caso de quienes trabajan con elementos clínicos y de laboratorio o dedicadas al cuidado de personas en clínicas u hospitales, en especial si están próximas a niños infectados, aunque esto último no se ha demostrado por completo. ${ }^{18}$

Es importante mencionar que el riesgo documentado de afección congénita por CMV a partir de una infección primaria de la madre durante la gestación, pues la transmisión transplacentaria en estos casos se presenta en una de cada tres embarazadas lo cual resalta la importancia de establecer el periodo relativo de adquisición de la infección, puesto que el riesgo incrementa cuando sucede durante el embarazo y disminuye si lo fue antes. ${ }^{17}$
De otro lado, las mujeres seronegativas en edad fértil, esto es entre 15 y 44 años, que han experimentado infección primaria tienen un alto riesgo de trasmisión placentaria del CMV. Así, las embarazadas que se han expuesto a niños con CMV tienen riesgo de adquirir la infección, puesto que ellos se convierten en foco primario. ${ }^{17}$

Los niños diseminan el virus a las superficies mucosas por periodos prolongados, pues se ha demostrado que tanto los sintomáticos como los que no lo son excretan el virus en la orina y la saliva durante muchos años después de su nacimiento. En la primera se ha detectado hasta los diez años, debido a la naturaleza crónica de la infección en los más pequeños, convirtiéndose en foco fácil del virus. ${ }^{17}$ Por lo anterior, las gestantes que han proporcionado cuidados a niños pequeños infectados un año antes del parto, incrementan la posibilidad de infección materna y en consecuencia la trasmisión del virus al feto. ${ }^{17}$

Otro factor de riesgo se asocia con la actividad sexual, pues en jóvenes el inicio temprano de esta facilita la infección congénita por CMV. ${ }^{17}$ Sin embargo, si transcurre un tiempo considerable entre la infección primaria y la gestación, el desarrollo de anticuerpos disminuye el riesgo de trasmisión transplacentaria. ${ }^{17}$ La tasa de transmisión maternofetal del virus se ve afectada, entre otros, por el trimestre gestacional de exposición al virus, la edad, así como el carácter de la inmunidad materna y la carga viral. En el primer trimestre los efectos neurológicos pueden ser más severos. ${ }^{13}$ Las mujeres con veinte o menos años de edad al momento del parto, la posibilidad es tres veces mayor de tener un bebe infectado. ${ }^{17}$ Por último la presencia de anticuerpos (inmunoglobina $G$ ) para la glicoproteína viral $\beta$, con posterioridad a una infección primaria, incrementa las probabilidades de bebes con pérdida de capacidad auditiva. ${ }^{17}$

\section{Inmunología y epigenética}

El feto y el RN tienen una alta susceptibilidad a infecciones virales. Un número de ellos, incluidos los citomegalovirus humanos (CMVH), herpes simple tipo 2, sincitial respiratorio (VSR) y el VIH, causan 
grave enfermedad progresiva en la vida temprana en comparación con una edad más avanzada. Aunque se acepta que esta se relaciona con inmadurez del sistema inmune, los mecanismos implicados siguen siendo poco conocidos. ${ }^{19}$

El RN requiere vacunas que lo protegen de tales infecciones, los linfocitos T CD8 juegan un papel central en la inmunidad mediante la producción de citocinas y eliminando células diana infectadas, pero es poco lo que se sabe acerca de la función de dichas células al principio de la vida. Las respuestas de estas al VIH y al VSR con frecuencia se detectan en lactantes infectados durante los primeros meses de vida. Se desconoce si dichas respuestas maduran con la edad..$^{20}$

Se ha demostrado que los linfocitos T CD8 pueden ampliar, diferenciar y adquirir funciones efectoras durante una infección viral y que esta respuesta tiene características muy similares a la de los adultos. La primera respuesta se puede medir a las 28 semanas de gestación, aunque puede desarrollarse aún más temprano durante la gestación. Se sabe poco acerca de la respuesta inmune primaria al CMVH. Existen datos de fetos de 28 semanas de edad que indican que durante la fase aguda las células T CD8 + tienen un fenotipo más similar a la inducida por otros virus persistentes, incluyendo el VIH, VEB, y el VHC, que se caracteriza por una proporción significativa de células altamente activadas en ciclo, la regulación por disminución de Bcl-2 y en algunos CD28 de baja regulación. ${ }^{20}$

El desarrollo de una respuesta madura y funcional $\mathrm{CD} 8+\mathrm{T}$ de los linfocitos al CMVH en el útero, sugiere que la maquinaria requerida para contrarrestar esas respuestas aparece temprano en la vida y podría ser utilizado para inmunizar a los RN contra las infecciones virales. ${ }^{20}$

Además del sistema inmune adaptativo, el embrión tiene resistencia potencial al CMV durante la primera embriogénesis. Las células madre son más resistentes a CMV que la mayoría de los otros tipos de células, aunque el mecanismo responsable no se entiende bien. Las células madre contienen menos ADN, esto puede reducir la capacidad de los CMVH a adherirse y entrar en la membrana celular, translocar al núcleo y atravesar la membrana nuclear de células madre pluripotenciales. Este hallazgo indicaría una nueva patogénesis de la anomalía congénita causada por el CMV. ${ }^{7}$

\section{Manifestaciones clínicas}

Es importante mencionar que la infección congénita por CMV es asintomática en la mayoría de los casos. ${ }^{21}$ Se pueden presentar diferentes manifestaciones neurológicas que comprometen a su vez múltiples órganos, en especial el sistema nervioso central y el retículo endotelio, cuyas lesiones por lo general son de carácter irreversible a diferencia de otros órganos. ${ }^{15}$

Cuando se trata de una infección congénita asintomática por $\mathrm{CMV}$, los menores tienen un mejor pronóstico de vida puesto que gran parte se deben a la reactivación del virus en la madre, de forma que el niño desarrolla anticuerpos protectores, a diferencia del RN prematuro que tiene menor cantidad de anticuerpos transferidos y más posibilidades de desarrollar la variedad sintomática. ${ }^{9}$

Los bebés asintomáticos pueden desarrollar pérdida de la capacidad auditiva y como consecuencia tendrán un déficit bilateral dependiendo de la severidad de la discapacidad. Así mismo se pueden presentar otros tipos de complicaciones neurológicas, como microcefalia, defectos neuromusculares y coriorretinitis, aunque aún no se ha demostrado su relación con problemas de aprendizaje y de comportamiento. ${ }^{21}$ No se han reportado estudios certeros que permitan predecir estos riesgos de pérdida de capacidad auditiva y otras secuelas, por lo que se requiere supervisión y seguimiento continuo. ${ }^{21}$

Un estudio realizado en Suecia en dos cohortes de niños con pérdida de la capacidad auditiva no hereditaria de etiología desconocida, uno con diferentes grados en 45 pacientes y la segunda de 46 con daño severo a profundo, en quienes se investigó ADN de CMV a través de la técnica de reacción en cadena de la polimerasa, mostró que en ambos grupos el 20\% de los niños fueron positivos y tres de la segunda cohorte 
presentaban mutación del Cx26, de donde se concluyó que la infección congénita de CMV representa un alto riesgo de compromiso auditivo en los niños. ${ }^{22}$

Algunos estudios, como el realizado en recién nacidos en Brasilia, han permitido sugerir la estrecha relación entre CMV y la pérdida de la capacidad auditiva no hereditaria, incluso en aquellas poblaciones con alta tasa de seroinmunidad materna al CMV. De forma que se encuentra una relación tanto en aquellos que se caracterizaron por infección congénita por CMV, como en los que la infección desarrollada por la madre fue previa a la gestación. ${ }^{23}$

En el caso de la infección congénita por CMV sintomática, la mayoría del compromiso ocurre en el SNC y el reticuloendotelial. Dentro de estas manifestaciones se encuentran hipotonía, ventriculomegalia, hipoplasia cerebelosa, polimicrogiria, paquigiria ${ }^{24}$, pseudoquiste periventricular, convulsiones, espasticidad, petequias, ictericia, hepatoesplenomegalia, retraso en el desarro$1 \mathrm{lo}^{21}$, neumonitis, hepatitis, enteritis, linfadenopatía y meningitis aséptica, estas dos con menor frecuencia. ${ }^{9}$

En más de dos tercios de los niños con infección por CMV las anomalías de neuroimagen comprenden calcificaciones en especial periventriculares, ventriculomegalia, alteración en la sustancia blanca, anomalías de migración, atrofia cortical, quistes periventriculares o hipoplasia cerebelosa. La tomografía computarizada normal del cerebro predice un desenlace clínico bueno, mientras que la microcefalia es el predictor más específico de secuelas neurológicas graves.

La RM es más sensible que la TAC cerebral en la detección de anomalías de la sustancia blanca, malformaciones corticales (agiria, lisencefalia, paquigiria, polimicrogiria), quistes periventriculares y displasia del hipocampo. Sin embargo, el papel pronóstico de estos hallazgos aún no está definido. Los patrones específicos han sido identificados en una pequeña cohorte de afección congénita CMV y se utilizan como criterios para la identificación en la RM de esta infección entre quienes cursan con leucoencefalopatía de origen desconocido. 5
En neonatos pretérmino se han evidenciado problemas respiratorios, como se describió en un reporte de Turquía, en el que se muestra progresión de una temprana enfermedad crónica pulmonar a la muerte, y se sugiere incluir esta complicación como manifestación clínica eventual en la infección materna recurrente por CMV. ${ }^{25}$

Se encuentran también manifestaciones de carácter oftalmológico, entre ellas coriorretinitis, estrabismo, microftalmia, atrofia del nervio óptico y discapacidad visual cortical. ${ }^{10}$ Se han reportado algunos hallazgos clínicos que muestran la implicación de los sistemas hepatobiliar y reticuloendotelial, como hiperbilirrubinemia conjugada, neutropenia, linfocitosis, anemia, trombocitopenia, colestasis y elevación de las transaminasas hepáticas. ${ }^{10}$

Al respecto, es interesante mencionar que manifestaciones como las de los niños con síndrome de blueberry muffin, que cursan con trombocitopenia, hiperbilirrubinemia, transaminasas elevadas y coagulopatía, se asociaban con rubéola congénita, pero un estudio presentado por Martins y col. evidenció que también se ven en infección congénita por CMV, por lo que el estudio de esta infección constituye una herramienta importante para el diagnóstico diferencial de los bebés blueberry. ${ }^{26}$

En el RN algunas de las manifestaciones de la infección son la apariencia séptica, apnea y bradicardia. En todo caso, como se ha mencionado, existe una tasa alta de mortalidad infantil y en quienes sobreviven a la infancia se ha reportado que se puede ver afectado su sistema psicomotor. ${ }^{9}$ Además, la infección es responsable de $4 \%$ de los hidrops fetales y forma parte del espectro de los hallazgos ecográficos de infección congénita, así como las calcificaciones cerebrales, el retraso de crecimiento, la hepatoesplenomegalia, el aumento de la ecogenidad intestinal, la microcefalia, la dilatación ventricular y la atrofia cortical. ${ }^{27}$

A pesar de que no existe asociación con cardiomiopatías, en la revisión de la literatura se encontró un reporte de caso del Hospital Kitano (Japón), de un recién nacido de dos meses de edad con falla cardíaca 
congestiva con infección congénita por CMV. La ecocardiografía mostró un daño en el ventrículo izquierdo. Si bien no se demostró que la cardiomiopatía fuese el resultado de una miocarditis fetal por CMV o si había ocurrido por un mecanismo fisiológico idiopático pues no se tomó biopsia de miocardio, los autores sugieren que fue causada por una exposición viral durante la gestación. ${ }^{28}$

\section{Diagnóstico}

Se realiza mediante la demostración del virus en los fluidos corporales, como orina o secreciones faríngeas, en las primeras tres semanas de vida. Después es difícil determinar si la infección era congénita o postnatal. El virus puede detectarse en cultivos de los fluidos (la rápida centrifugación lo facilita y se requieren 24 horas de incubación) o por PCR. Los anticuerpos no son útiles en el diagnóstico de CMV congénito neonatal porque la IgG indica una infección materna, sin poderse determinar cuando ocurrió. Las pruebas para IgM tienen baja sensibilidad y especificidad. ${ }^{29}$

\section{Infección materna}

En la embarazada la demostración de seroconversión IgG es el mejor método para el diagnóstico de primoinfección por CMV; sin embargo, casi nunca se dispone del par de sueros obtenidos en la fase aguda y convaleciente, pues suele cursar de modo asintomático. La detección de IgM en una única muestra de suero es indicativa de infección; pero la posibilidad de su persistencia hasta por diez meses, la posible aparición en reactivaciones y reinfecciones y las reacciones falsas positivas dificultan la interpretación de un resultado positivo aislado. ${ }^{30}$

Ante un resultado positivo para $\operatorname{IgM}$ y en ausencia de $\mathrm{IgG}$, es necesario repetir las pruebas pasadas dos a tres semanas con el objeto de demostrar seroconversión; si en la segunda muestra el resultado de IgG sigue negativo, se considerará la IgM un falso positivo. En el caso de un resultado positivo para $\mathrm{IgM}$ e $\mathrm{IgG}$ es necesario recurrir a ensayos de avidez de $\mathrm{IgG}$, pues son útiles para distinguir una infección primaria de una pasada o recurrente, y pueden ayudar a datar el momento de la infección. La presencia de anticuerpos $\operatorname{IgG}$ de alta avidez indicaría una infección antigua (de al menos tres meses) y, por tanto, la presencia de $\operatorname{IgM}$ podría deberse a una reactivación o incluso a una reinfección. Por el contrario, un índice de avidez bajo sugiere una primoinfección reciente. Si se establece este último diagnóstico en la gestante, es aconsejable realizar estudios diagnósticos en el feto y el RN.

\section{Infección fetal}

Para el diagnóstico prenatal de infección por CMV en el feto, el método de referencia es la detección del virus en el líquido amniótico por cultivo o PCR. Este ha de tomarse alrededor de la semana 22 de gestación, siendo recomendable que transcurran al menos seis semanas desde la fecha de la infección materna. ${ }^{12}$

La sensibilidad de la PCR es muy buena (95\%) y superior al cultivo. La especificidad de ambos métodos es excelente. Los resultados falsos negativos pueden producirse si la toma de la muestra se realiza en la fase temprana, antes de que se elimine el virus por la orina al líquido amniótico. Otra prueba disponible es la detección de IgM específica en sangre fetal. Sin embargo, el hecho de que la cordocentesis sea más invasiva que la amniocentesis, unido a la baja sensibilidad, no la hacen recomendable.

\section{Infección congénita}

Al nacimiento la detección de $\operatorname{IgM}$ en sangre del RN sólo permite diagnosticar entre 50 y $70 \%$ de las infecciones congénitas por CMV, por lo que su negatividad no excluye el diagnóstico. La presencia de IgG es de poca utilidad, pues puede reflejar el paso de anticuerpos maternos a través de la placenta. La detección del virus por cultivo o PCR en muestras de orina, sangre, saliva u otros fluidos biológicos en las dos primeras semanas de vida son los procedimientos diagnósticos de elección. En las muestras a las dos semanas del nacimiento, la detección de CMV puede reflejar la 
adquisición en el canal del parto o a través de la leche materna y por tanto no son útiles para el diagnóstico de la infección congénita.

El cultivo tradicional puede demorar hasta catorce días, por lo que en la práctica ha sido sustituido por la técnica shellvial, que permite el diagnóstico viral en 24 a 48 horas con sensibilidad de $94,5 \%$ y especificidad de $100 \%$. La PCR a partir de muestras de sangre y orina ha mostrado valores de sensibilidad del $100 \%$, con una excelente especificidad, por lo que un resultado negativo descarta la infección. ${ }^{30}$

Por otro lado se ha analizado la presencia de ADN de CMV en la leche materna y muestras de saliva en madres a los seis días después del parto, encontrando que el momento de recogida de las muestras es fundamental para garantizar la correcta utilización de la saliva. Como recurso es posible recoger orina sobre papel de filtro colocado en el pañal. ${ }^{31}$

\section{Infección neonatal}

El diagnóstico de infección neonatal adquirida en el $\mathrm{RN}$ puede realizarse con las mismas técnicas de laboratorio que se usan en la congénita. Los que adquieren el CMV durante el nacimiento o el periodo posnatal no diseminan el virus antes de las tres semanas, por lo que la detección primaria del CMV en este periodo se considera prueba de infección congénita. La de infección intraparto o postnatal requiere una prueba negativa para el virus en las tres primeras semanas de vida cuya madre sea seronegativa en el parto y luego detectado el virus en una muestra posterior. A partir de la tercera semana se dificulta diferenciar entre una infección congénita y adquirida. ${ }^{32}$

A fines de 1985 se desarrolló la técnica de reacción en cadena de la polimerasa (PCR, por sus siglas en inglés), ${ }^{33}$ que permitió en 1994 el diagnóstico de $\mathrm{CMVH}$ en muestras de sangre de RN, en comparación con el método de aislamiento viral. Este proceso fue simplificado por Barbi y col. en el año 2000, quienes aplicaron esta técnica en gotas de sangre seca del talón del RN, recolectadas sobre papel de filtro, ${ }^{34}$ cuya sensibilidad fue de $100 \%$ y especificidad de $99 \%$, en comparación con el aislamiento viral. ${ }^{35}$
Lo anterior sugiere que existe la posibilidad de realizar tamizaje neonatal a partir de sangre seca del RN. Sin embargo, no existe un protocolo para la vigilancia de niños con resultados de CMV positivo, además el costo psicológico de los padres al generar ansiedad debe considerarse debido a que en cerca del $80 \%$ de infectados no existe una relación de discapacidad con la positividad de CMV, lo que hace que los padres a pesar del beneficio algunos prefieren oponerse a la práctica del tamizaje. ${ }^{36}$

Los beneficios potenciales de la detección son convincentes. En dos tercios de los niños con discapacidad neurológica se logra documentar infección congénita por CMV siendo asintomáticos al nacer, por lo que el tamizaje ayudaría a identificar aquellos que requieren intervención temprana y además proporciona datos necesarios de la historia natural de la afección. El tamizaje crea conciencia y proporciona referencias en tasas de prevalencia de CMV congénito que podrían ayudar al desarrollo de una vacuna. ${ }^{37}$

Para el tamizaje se ha reportado la utilidad de una muestra seca de orina Así mismo una muestra seca de orina para la cuantificación de CMV. Este método estandarizado puede facilitar los estudios de CMV en las áreas de recursos limitados y permitir la vigilancia longitudinal de cargas virales en los niños tratados. ${ }^{38}$

El diagnóstico rápido y correcto puede ayudar al pediatra a llevar a cabo el tratamiento apropiado y el manejo de casos en particular. Muchos son sintomáticos sin evidencia florida de infección, lo cual dificulta valorar el verdadero impacto. La detección por Elisa en mujeres embarazadas ayudaría a los obstetras a tomar decisiones informadas con respecto a embarazos complicados por la infección por CMV. ${ }^{39}$

\section{Tratamiento}

El medicamento ideal para el manejo de la infección por CMV debe tener la capacidad de controlar la replicación dinámica del virus y proporcionar seguridad para su uso prolongado, permitiendo la profilaxis en pacientes trasplantados, con VIH y pediátricos por varios meses; además asegurar la biodisponibilidad oral en caso de resistencia. Así mismo, la composi- 
ción del virus no deberá requerir anabolismo o ser degrada en el huésped, ni tampoco interferir con la actividad metabólica enzimática como en el caso del citocromo P450. ${ }^{40}$

En el tratamiento de la infección congénita por CMV, el uso de antivirales como ganciclovir (GCV) y valganciclovir (VGCV) se recomienda en RN sintomáticos durante los 30 primeros días de vida con enfermedades orgánicas severas o del SNC. ${ }^{41,42}$

El empleo de ganciclovir intravenoso durante seis semanas previene el desarrollo de hipoacusia en infección congénita sintomática por CMV, pero si es superior a este tiempo, pese a los beneficios, puede conllevar los efectos adversos de un acceso venoso prolongado. ${ }^{43}$

El uso de valganciclovir oral es una buena opción después del periodo natal, prolongándolo al menos hasta un año ya que puede mejorar e incluso preservar la función auditiva. ${ }^{44}$

\section{Manejo del RN con infección congénita por CMV}

Los informes de casos individuales han mostrado beneficios clínicos y virológicos con ganciclovir. Recomendación grado D: aquellos con peligro de infección deben considerarse para el tratamiento inmediato. ${ }^{45}$

\section{Neonato con compromiso del SNC}

Dos estudios de nivel uno han demostrado que el tratamiento con ganciclovir mejora el desarrollo neurológico en 24\%, la alteración de la audición se reduce o se estabiliza en un $84 \%$ y la agudeza visual mejora en $70 \%$ de los casos. ${ }^{45}$ Recomendación grado A: Los RN con compromiso del SNC siempre deben ser tratados como el neonato con infección diseminada y CMVH carga viral alta, petequias o trombocitopenia. La infección diseminada CMVH al nacer se define como la presencia de RCIU asimétrica, hepatoesplenomegalia, hepatitis, hiperbilirrubinemia y anemia; de ellos 40 a 50\% mostrarán evidencia de difusión de la infección después del nacimiento. ${ }^{45}$ Recomendación grado B: no se ha establecido un tratamiento que explique las diferencias en las técnicas utilizadas para determinar la carga viral, por ello en caso de infección diseminada y alta carga viral se recomienda el tratamiento, ya que puede afectar a largo plazo del desarrollo neurológico. ${ }^{45}$

Aunque existe la posibilidad de que el RN asintomático pueda desarrollar secuelas a largo plazo, los riesgos y efectos secundarios relacionados con la terapia con ganciclovir pueden ser mayores y se desconoce el beneficio a largo plazo. Recomendación grado B: en la actualidad no se recomienda el tratamiento de los neonatos asintomáticos. ${ }^{45}$

\section{Tratamiento del RN con infección congénita por CMV}

El manejo del CMVH sintomático se ha hecho con diversos agentes antivirales, la mayoría tóxicos potenciales. Hoy se prefiere el ganciclovir por vía intravenosa $6 \mathrm{mg} / \mathrm{k}$ dos veces al día durante seis semanas. ${ }^{45}$ Después del primer mes de vida valganciclovir, que es la biodisponibilidad oral profármaco de ganciclovir, ha recibido mucha atención. Se ha demostrado que tiene diez veces más biodisponibilidad oral, que el ganciclovir por la misma vía (53,6\% vs $4,8 \%)$. Una vez absorbido se convierte en ganciclovir por esterasas gastrointestinales y hepáticas. Las pruebas en los RN valganciclovir es creciente y los datos farmacocinéticos recomiendan una dosis de $15 \mathrm{mg} / \mathrm{k}$ dos veces al día. El efecto secundario predominante es la neutropenia aguda (de grado tres a cuatro) hasta en $63 \%$ con ganciclovir y un $38 \%$ con valganciclovir. Otros efectos secundarios raros son la supresión de la médula ósea, el aumento de enzimas hepáticas, alteración renal e hipopotasemia. Todos son reversibles después de suspender el medicamento por al menos tres a siete días o al reducir la dosis. ${ }^{45}$

La US-FDA ha clasificado el ganciclovir como medicamento categoría $\mathrm{C}$ en el embarazo. Se ha usado en retinitis por CMV y en la prevención de la enfermedad por CMV en pacientes pediátricos con trasplante durante muchas décadas. No se ha informado en casos con cáncer. Tampoco está claro si la terapia prolongada o repetida por más de seis semanas es necesaria ya que la excreción del virus regresa a un ni- 
vel de carga viral más baja después de la interrupción del tratamiento. ${ }^{45}$

Grado de recomendación B: todos los niños que reciben ganciclovir o valganciclovir inicial deben ser controlados de cerca por el desarrollo de efectos secundarios en las primeras semanas. El tratamiento puede iniciarse con ganciclovir intravenoso $6 \mathrm{mg} / \mathrm{k}$ dos veces al día para pasar a la vía oral una vez que la concentración se estabiliza. No se recomienda una duración mayor de seis semanas. ${ }^{45}$

\section{Seguimiento}

A largo plazo los estudios epidemiológicos han demostrado que 40 a $58 \%$ de los lactantes sintomáticos y $13,5 \%$ de los asintomáticos con $\mathrm{CMVH}$ tendrán secuelas neurológicas permanentes. La infección es progresiva y en la fase tardía causa disminución de la audición. El tiempo exacto para esta pérdida progresiva no se puede determinar. La evaluación ayuda a identificar la pérdida temprana pero no logra diagnosticar la de comienzo tardío, que puede ocurrir durante los primeros seis años de vida. La infección congénita por CMV también puede en el largo plazo conducir a discapacidad visual.

Recomendación: grado B: todos los niños sometidos o no a tratamiento deben tener una evaluación regular auditiva, oftalmológica y neurológica para la detección del deterioro cognitivo y del desarrollo neurológico, así como de la pérdida de la capacidad auditiva no hereditaria..$^{45}$

Es muy importante el tratamiento preventivo contra la infección congénita, que incluye cambios en el comportamiento higiénico en gestantes seronegativas, administración de inmunoglobulina hiperinmune en aquellas con infección primaria y vacunas para niñas y mujeres previas al embarazo. El desarrollo de la vacuna Town strain incluye el mayor uso de glicoproteina B para CMV y un adyuvante MF/59.46,47

El riesgo de transmisión de CMV de la madre al feto se reduce en forma sensible por la inmunidad natural adquirida, induciendo una potente neutralización de los anticuerpos contra la infección de fibroblastos y células epiteliales. ${ }^{48}$ La prevención es una acción importante contra la transmisión del CMV, mediante campañas de salud pública en busca de cambios en la higiene de futuras o actuales gestantes, en especial cuando tienen contacto en el cuidado diario de niños pequeños portadores de $\mathrm{CMV} .{ }^{49,50}$

\section{Conclusiones}

En la infección congénita por CMV se evidencian estudios y reportes con miras a caracterizar su historia natural, que dan cuenta de la presencia de diversos factores de riesgo tanto en la mujer gestante como el neonato, de manera que el diagnóstico oportuno permite adoptar el tratamiento adecuado. En este orden, se recomienda el uso de ganciclovir seguido de tratamiento prolongado con valganciclovir oral, que tiene la bondad de mantener el efecto persistente de la droga antiviral sin deterioro de la capacidad auditiva, aun después de terminado el tratamiento. ${ }^{51}$ Se hace énfasis en la necesidad de adelantar buenas prácticas para la prevención y así reducir la morbi-mortalidad devastadora a causa de esta infección congénita, lo que generaría cambios relevantes en la formulación eficiente de políticas de salud pública.

\section{Referencias}

1. Lazzarotto T, Lanari M. Why is cytomegalovirus the most frequent cause of congenital infection?. Expert Rev Anti Infect Ther. 2011 Oct; 9(10):841-3.

2. Buonsenso D, Serranti D, Gargiullo L, Ceccarelli M, Ranno O, Valentini P. Congenital cytomegalovirus infection: current strategies and future perspectives. Eur Rev Med Pharmacol Sci. 2012 Jul; 16(7):919-35.

3. Sinzger C, Grefte A, Plachter B, Gouw AS. Fibroblasts, epithelial cells, endothelia cells and smooth muscle cells are major targets of human cytomegalovirus infection in lung and gastrointestinal tissues. J Gen Virol. 1995 Apr; 76 (Pt 4):741-50.

4. Rodríguez M, Juárez G, Astudillo J, Hasbún J, Parra M. Infección congénita por citomegalovirus: nuevos aspectos terapéuticos. Rev. chil. obstet. ginecol. 2008:73(6): 402-5.

5. Manara R, Balao L, Baracchini C, Drigo P, D'Elia R, Ruga EM. Brain magnetic resonance findings in symptomatic congenital cytomegalovirus infection. Pediatr Radiol. 2011: 41:962-70.

6. Cannon MJ, Hyde TB, Schmid DS. Review of cytomegalovirus shedding in bodily fluids and relevance to congenital cytomegalovirus infection. Rev Med Virol. $2011 \mathrm{Jul} ; 21(4): 240-55$

7. Kawasaki H. Pluripotent stem cells are protected from cytomegalovirus infection at multiple points: implications of a new pathogenesis for congenital anomaly caused by cytomegalovirus. Congenit Anom (Kyoto). 2012 Sep; 52(3):147-54. 
8. Vide Tavares M, Domingues AP, Tavares M, Malheiro E, Tavares F, Moura P. Cytomegalovirus: is there a place for screening during pregnancy?. Acta Med Port. 2011 Dec; 24 Suppl 4:1003-8.

9. Alarcon Allen A, Baquero-Artigao F. Review and guidelines on the prevention, diagnosis and treatment of post-natal cytomegalovirus infection. An Pediatr (Barc). 2011 Jan; 74(1):52.e1-52.e13

10. Lim SL, Tan WC, Tan LK. Awareness of and attitudes toward congenital cytomegalovirus infection among pregnant women in Singapore. Int J Gynaecol Obstet. 2012 Jun; 117(3):268-72.

11. Boppana SB, Rivera LB, Fowler KB, Mach M, Britt WJ. Intrauterine transmission of cytomegalovirus to infants of women with preconceptional immunity. N Engl J Med. 2001 May 3; 344(18):1366-71.

12. Alarcon A, Baquero F, Figueras $\mathrm{N}$ et al. Consensus document from the Spanish Society of Paediatric Infectious Diseases (SEIP) on the diagnosis and treatment of congenital cytomegalovirus infection. An Pediatr (Barc). 2009 Dec;71(6):535-47.

13. Kenneson A, Cannon MJ. Review and meta-analysis of the epidemiology of congenital cytomegalovirus (CMV) infection. Rev Med Virol. 2007 Jul-Aug; 17(4):253-76

14. Tian C, Ali SA, Weitkamp JH. Congenital Infections, Part I: Cytomegalovirus, Toxoplasma, Rubella, and Herpes Simplex. NeoReviews. 2010; 11:e436-e446.

15. Cheeran MC, Lokensgard JR, Schleiss MR. Neuropathogenesis of congenital cytomegalovirus infection: disease mechanisms and prospects for intervention. Clin Microbiol Rev. 2009 Jan;22(1):99-126.

16. Rodríguez M. Juárez G, Astudillo J, HasbúnJ, Parra M. Infección congénita por citomegalovirus: nuevos aspectos terapéuticos. REV CHIL OBSTET GINECOL 2008; 73(6): 402 - 405.

17. Coll O, Benoist G, Ville Y, Weisman LE, Botet F, Anceschi MM, et. al. Guidelines on CMV congenital infection. J Perinat Med. 2009; 37(5):433-45.

18. Luck S, Sharland M. Postnatal cytomegalovirus: innocent bystander or hidden problem?. Arch Dis Child Fetal Neonatal Ed. 2009 Jan; 94(1):F58-64.

19. Mofenson LM, Brady MT, Danner SP, Dominguez KL, Hazra R, Handelsman E, et. al. Guidelines for the Prevention and Treatment of Opportunistic Infections among HIV-exposed and HIV-infected children: recommendations from CDC, the National Institutes of Health, the HIV Medicine Association of the Infectious Diseases Society of America, the Pediatric Infectious Diseases Society, and the American Academy of Pediatrics. MMWR Recomm Rep. 2009 Sep 4; 58(RR-11):1-166.

20. Marchant A, Appay V, Van Der Sande M, et. al. Mature CD8 (+) T lymphocyte response to viral infection during fetal life. J Clin Invest. 2003 Jun; 111(11):1747-55.

21. Ross SA, Boppana SB. Congenital cytomegalovirus infection: outcome and diagnosis. Semin Pediatr Infect Dis. 2005 Jan; 16(1):44-9.

22. Karltorp E, Hellstrom S, Lewensohn-Fuchs I, Carlsson-Hansen E, Carlsson PI, Engman ML. Congenital cytomegalovirus infection - a common cause of hearing loss of unknown aetiology. Acta Paediatr. 2012 Aug; 101(8):e357-62.

23. Yamamoto AY, Mussi-Pinhata MM, Isaac Mde L, et. al. Congenital cytomegalovirus infection as a cause of sensorineural hearing loss in a highly immune population. Pediatr Infect Dis J. 2011 Dec; 30(12):1043-6.

24. Malm G, Grondahl EH, Lewensohn-Fuchs I. Congenital cytomegalovirus infection: a retrospective diagnosis in a child with pachygyria. Pediatr Neurol. 2000 May; 22(5):407-8

25. Koklu E, Karadag A, Tunc T, Altun D, Sarici SU. Congenital cytomegalovirus infection associated with severe lung involvement in a preterm neonate: a causal relationship?. Eur J Pediatr. 2009 Nov; 168(11): 1409-12.

26. Martins S, Rocha G, Silva G, Calistru A, Pissarra S, Guimaraes H. Blueberry muffin baby. A rare presentation of congenital cytomegalovirus Infection. Acta Med Port. 2011 Dec; 24 (Suppl 3):703-8.

27. Campos Arca S, Fernández Rial M, Pardo Pumar I, Luaces C, García Piñó J, Moral Santamarina E. Hidrops fetal por infección congénita por citomegalovirus: tratamiento posneonatal prolongado con valganciclovir. Rev Chil Obstet Ginecol. 2012; 77(1): 44-49.

28. Sakaguchi H, Yamamoto T, Ono S, Akashi A, Tsuda E, Watanabe K. An infant case of dilated cardiomyopathy associated with congenital cytomegalovirus infection. Pediatr Cardiol. 2012 Jun; 33(5):824-6.

29. Del Pizzo J. Focus on diagnosis: congenital infections (TORCH). Pediatr Rev. 2011 Dec; 32(12):537-42.
30. Sampedro Martinez A, Martinez LA, Teatino PM, Rodriguez-Granger J. Diagnosis of congenital infection. Enferm Infecc Microbiol Clin. 2011 Dec; 29 Suppl 5:15-20.

31. Koyano S, Inoue N, Nagamori T, Moriuchi H, Azuma H. Newborn screening of congenital cytomegalovirus infection using saliva can be influenced by breast feeding. Arch Dis Child Fetal Neonatal Ed. 2013 Mar;98(2):F182.

32. Pass RF. Diagnosis and management of cytomegalovirus infection in the newborn. Pediatr Ann. 2002 Nov; 31(11):719-25.

33. Lim SL, Tan WC, Tan LK. Awareness of and attitudes toward congenital cytomegalovirus infection among pregnant women in Singapore. Int J Gynaecol Obstet. 2012 Jun; 117(3): 268-72

34. Distéfano A, González CA, Pardón F, Sarubi MA, Canero-Velazco C. Diagnóstico de la infección congénita por citomegalovirus en muestras de sangre seca de recién nacidos en la tarjeta de Guthrie. Una técnica promisoria. Arch Argent Pediatr. 2008; 106(2):132-137.

35. Sinzger C, Grefte A, Plachter B, Gouw AS, The TH, Jahn G. Fibroblasts, epithelial cells, endothelial cells and smooth muscle cells are major targets of human cytomegalovirus infection in lung and gastrointestinal tissues. J Gen Virol. 1995 Apr; 76 (Pt 4):741-50.

36. Din ES, Brown CJ, Grosse SD, et. al. Attitudes toward newborn screening for cytomegalovirus infection. Pediatrics. 2011 Dec; 128(6):e1434-42.

37. Kharrazi M, Hyde T, Young S, Amin MM, Cannon MJ, Dollard SC. Use of screening dried blood spots for estimation of prevalence, risk factors, and birth outcomes of congenital cytomegalovirus infection. J Pediatr. 2010 Aug; 157(2):191-7.

38. Forman M, Valsamakis A, Arav-Boger R. Dried urine spots for detection and quantification of cytomegalovirus in newborns. Diagn Microbiol Infect Dis. 2012 Aug; 73(4):326-9.

39. Gandhoke I, Aggarwal R, Hussain SA, et. al. Congenital CMV infection; diagnosis in symptomatic infants. Indian J Med Microbiol. 2009 Jul-Sep; 27(3):222-5.

40. Griffiths PD. The 2001 Garrod lecture. The treatment of cytomegalovirus infection.J Antimicrob Chemother. 2002 Feb; 49(2):243-53

41. Kadambari S, Williams EJ, Luck S, Griffiths PD, Sharland M. Evidence based management guidelines for the detection and treatment of congenital CMV. Early Hum Dev. 2011 Nov; 87(11):723-8.

42. Kimberlin DW, Acosta EP, Sanchez PJ. Pharmacokinetic and pharmacodynamic assessment of oral valganciclovir in the treatment of symptomatic congenital cytomegalovirus disease. J Infect Dis. 2008 Mar 15; 197(6):836-45.

43. Baquero-Artigao F, Romero Gomez MP. Prolonged treatment with valganciclovir in an infant with congenital cytomegalovirus infection. An Pediatr (Barc). 2009 Jun; 70(6):578-81.

44. del Rosal T, Blazquez D, Noguera-Julian A, et. al. Treatment of symptomatic congenital cytomegalovirus infection beyond the neonatal period. J Clin Virol 2012 Sep; 55(1):72-4.

45. Gandhi RS, Fernández-Álvarez JR, Rabe. H. Management of congenital cytomegalovirus infection: an evidence-based approach. Act Pediatr. 2010 99:509-15.

46. Adler SP, Nigro G, Pereira L. Recent advances in the prevention and treatment of congenital cytomegalovirus infections. Semin Perinatol. 2007 Feb; 31(1):10-8.

47. Griffiths PD. Burden of disease associated with human cytomegalovirus and prospects for elimination by universal immunisation. Lancet Infect Dis. 2012 Oct; 12(10):790-8.

48. Wang D, Li F, Freed DC, et. al. Quantitative analysis of neutralizing antibody response to human cytomegalovirus in natural infection. Vaccine. 2011 Nov 8; 29(48):9075-80

49. Korver AM, de Vries JJ, Oudesluys-Murphy AM. Congenital cytomegalovirus infection: prevention is better than treatment. J Pediatr. 2011 Nov; 159(5):877.

50. Noyola DE, Matienzo-Serment L, Rodriguez-Vidal SO, Ochoa-Perez UR, PinaGranja JM, Garcia-Sepulveda CA. Congenital cytomegalovirus infection in newborn infants from the state of San Luis Potosi, Mexico. Salud Publica Mex. 2011 Nov-Dec; 53(6):513-5.

51. Amir J, Wolf DG, Levy I. Treatment of symptomatic congenital cytomegalovirus infection with intravenous ganciclovir followed by long-term oral valganciclovir Eur J Pediatr. 2010 Sep; 169(9):1061-7. 